\title{
Making MNC Competitive Through Effective Cross Cultural Negotiations
}

\author{
Yezdi H. Godiwalla ${ }^{1}$ \\ ${ }^{1}$ Formerly of: Management Dept., College of Business and Economics, University of Wisconsin-Whitewater, USA \\ Correspondence: Yezdi H. Godiwalla, Formerly of: Management Dept., College of Business and Economics, University \\ of Wisconsin-Whitewater, USA.
}

Received: November 30, 2018

Accepted: December 17, 2018

Available online: December 21, 2018

doi:10.11114/ijsss.v7i1.3893

URL: https://doi.org/10.11114/ijsss.v7i1.3893

\begin{abstract}
An organization exists in the context of other entities (such as other organizations and governmental, political and social entities) in its organizational environments. The organization's focal entities become its task environments that require its immediate attention and it has to interact with all such entities so that it is able to satisfy their expectations from it, and, in turn, by pursuing its strategy, it achieves its own goals. This is the model that describes the situation of any organization, including a multinational corporation (MNC) in its international and multi-cultural setting. Often, the negotiation process for meeting an organization's needs may involve managing inherent conflict, disagreement or competing for constrained resources, thus making negotiation an arduous process. The very basis of give-and-take interactions and negotiations across different cultures, that typify an MNC in its multi-cultural setting, becomes the foundation for cross cultural negotiations. Such negotiations provide the MNC the method of communicating with its diverse entities and seek the services from them for it to achieve its goals. Because an MNC operates in an international and multi-cultural setting, its many entities are of diverse nature and cross cultural communication and negotiation skills become the critical. The inter-organizational interactions of an MNC in its international and multicultural setting become the basis of its day-to-day operations.
\end{abstract}

Keywords: MNC competitiveness, cross cultural negotiations for organizational performance, inter-organizational interactions and negotiation

Dependence (and, inter-dependence among a group of entities), as a concept, is closely associated with bargaining and negotiation. Our dependence on others makes us interact with them and negotiate with them for us to achieve our goals. Our dependence on others in achieving our goals makes us communicate with them and negotiate our terms of engagement with them, and then serve them for meeting their terms. In turn, we derive the needed services from them as we strive to satisfy our needs and achieve our goals. Such an approach is mutually satisfying because both sides benefit in the process. Negotiation is an everyday and everywhere activity.

Cultural cohesiveness and closeness bring about similarities of values and ideas. Even such coziness, within the same social nest, brings about the differences and conflicts of needs and so raises the need for seeking concessions and favors among family and friends. It becomes a give-and-take interaction as each entity seeks favors. As we communicate and negotiate, we feel our limits of influence and freedom of choice, and, we often keep on wanting to increase them with others around us. Subordinates seek favors from their superiors and vice versa as they prosecute their duties. Customer organizations seek special terms from their suppliers to better suit their needs and, in turn, suppliers seek better terms from their customer organizations to better suit their needs.

\section{Definition of Negotiation}

We may define negotiation in many ways. We may define it as the process of discussion (among two or more parties who have similar yet conflicting interests) as the parties interact to achieve their own interests and a mutually acceptable deal, settlement or agreement (Moran and Stripp, 1991). Collins English Dictionary (2012) defines it as the close and intense interactions among the parties to achieve the sought after goal of a viable and common accord.

There are nuances among the synonyms: negotiation, arrange concert. Merriam-Webster's Dictionary of Synonyms (1984, p.560), when comparing negotiation with arrange and concert, defines negotiation as more as the process to arrive at a joint agreement among the parties that is achieved through intense interaction and give-and-take. It further states that negotiation is more attributable to higher levels of official settings of the state and politics. An example could 
be the US Secretary of State negotiating with the Foreign Minister of another country to agree on the new terms of foreign trade.

To continue Merriam-Webster's (1984, p. 186), bargaining, on the other hand, focuses on the intense interactions between parties to seek a concord regarding buying and selling of objects, products as in the business sense. An example could be Company A and Company B after much intense interactions, which lasted a week, finally settled upon the terms for the former to sell its Illinois factory to the latter for a specific sum of money. The fruition of such bargaining would lead to an agreement or settlement of previously disagreed (or, un-agreed) upon issues. It is hoped that the agreement be lasting, especially if it is perceived to be equitable and mutually beneficial to both parties.

\section{Negotiation in Everyday Life and in Business}

When we negotiate even within the same circles entity or social, political or business groups, which we feel we understand, such as the members of the same professional association or even the same filial or relations circles, we usually understand the process and the personalities of the various peoples involved, and, we somehow feel or predict the manner of our intended communicate styles and content because we probably judge anticipate the nature of the other party's likely reception of our views, ideas and suggestions. For example, a young boy will know how his mother will respond for a specific request, and it could be different from how his father would re for the same request; and, in knowing so, he modifies the content and the manner of his request depending to whom he is addressing his request. Accordingly, if so needed as in the case of the perceived unviability of the requests to either parent, he would review his goals and change them and his request when dealing with one or the other parent depending on the perception of how the persons would respond to our requests. We subjectively judge and modify our negotiation, both its content and process. We do so quite intuitively in our daily lives. Subordinates seek favors from their superiors and vice versa as they prosecute their duties. Customer organizations seek special terms from their suppliers to better suit their needs and, in turn, suppliers seek better terms from their customer organizations to better suit their needs.

One inference to learn from the above discussions for the international business settings is that the international business executive or negotiator would have to modify and even change his goals, content and manner of negotiation as he deals with different national or regional cultures. Negotiation across cultures requires him to be familiar with the preferred negotiation styles of the country in which he is negotiation. His negotiation maneuvers in China, on the one hand, would have to be very different than those in United Kingdom or Sweden, on the other hand, because there are wide gaps in cultural norms and business practices and etiquettes among these countries. His communication styles and his appeals in the intense interactions would have to be dramatically changed.

If we consider a good bargaining process should be focused on achieving specific objectives for both parties of the negotiation in a manner of arriving at a mutually acceptable common ground for both parties, it becomes a focused and even an intense process. Such intense interactions may get stalled and may need a nudge to move them forward. Ideally, there would be accommodations or give and take on both sides. Otherwise, it would be a one-sided negation process. Ideally, there would be mutual understand on both parties and a genuine understanding and accommodation to help each other out. Such a systematic process would have a higher level of mutual empathy and capacity to iron out thorny, difficult issues through better willingness to help each other.

The purposes of negotiations can be for a variety of business issues: (a) seeking newer suppliers or renewing current supplies, (b) making newer or repeat sales, (c) international collaborations, partnerships and joint ventures, (d) managerial, technical and financial cooperation, (e) seeking agreements on turn-key projects, (f) seeking approvals of federal, state and local governmental permits and licenses and other legal contracts, (h) inter-organizational agreements involving assembling, channel distribution agreements, and (i) contract labor and facilities management agreements. Often, multiple purposes can complicate because they would engender multiple, often conflicting goals. These can confound the negotiator who may then have to configure the hierarchy of goals.

\subsection{Challenges in Negotiation}

Negotiation challenges may appear at the inception to be difficult at times in the different stages of the negation process and it is a long an unpredictable journey. Negotiations agreements, for them to be enduring, must minimally meet the threshold of satisfaction on all sides, That is to say, one party, no matter however powerful a hand it has, should not take undue advantage of its position and pressure the other party (or, parties) to accept into an unnatural and unfair submission. Such an agreement, in which one party has accepted the terms under duress, is unfair and faulty. Such an agreement will not be a happy one and it will not last. The party, which had the lower hand at the time of the negotiation and agreement, will later struggle to improve its stand and will pull out (or, at least, tend to pull out) of the agreement with party which at that time had the upper hand. In the context of this viewpoint and further commenting on effective negotiation process, Fells et al (2015) state that fuller exchange and sharing of information and data and openly exchanging each party's goals and "the ideal" solution and then sincerely working out an acceptable compromise accord 
would result in a more realistic and satisfying solution to both parties.

In the modern day business we have large international business activities and so the much of the transactions are international (Moran and William, 1991). This places more complex challenges upon a firm to deal with other parties from other countries, often from very culturally different countries. Each country culture has its own social; and, it has its own specific and practiced ways for business transactions and communication (Situmorang and Japutra, 2019). The skilled, experienced international business executive and negotiator is versatile and he has focused tailored approaches to suit each country culture as he involves himself in intense interactions with the parties for the specific country culture.

\section{Successful Negotiation Approaches}

Successful negotiation is not an unfair use of competitive advantage to the gross detriment of the other party; it is not insensitive, pressuring or demanding types of interaction to generate the desired outcome. It is not an unfair use of power as in the case of a large MNC from an advanced country dealing with a much smaller firm in a developing country. It is a better than that. It is a careful and fuller study of the knowing the situation of the people with whom he is communicating and understanding in order to arrive at a mutually acceptable agreement. Successful negotiation means proper understanding of the issues and their implications. It requires for the international executive or negotiator to put him in the other persons' shoes and correctly judge the desired collaborative approach which would bring about a fusion of strategies for a suitable and equitable agreement. It would require offering proper help and a kinder communication style which is likely to elicit a more complete and frank response from the other people.

Successful negotiation among the two parties requires better understanding, more than basic understanding; even better empathy, of the other parties' needs and views, even though the cultural and social circumstances, because of the complexities involved, may prove to be major obstacles in such understanding. Successful negotiation is enhanced where there is sustained high empathy, sincerity and genuine concern for others' interests. This should be followed by a willingness to help over and above the normal course of actions often if even if these interests are at variance with the larger firm with more power. In the context of a particular country's culture, the inherent social issues can have a complex effect in that multiple pressures can impact the negotiation outcome as in the case of a Brazilian study by Fang, Schaumburg, and Fjellström (2017).

Negotiation requires not only understanding and empathy, but also patience, persistence, and preparation and hard work (before and after the actual negation process). It requires the ability to correctly feel the pulse of the other parties and to judge the preferred pace of the other parties and the choice of intensity of discussion, such as whether to be intensely involved in details, or, less involved in details, or, instead, be more light hearted in discussions and more human-to-human in approach.

\section{Inter-personal Confidence and Mutual Trust}

In many warm or emotional cultures, a strong feeling of inter-personal confidence and mutual trust are prerequisites for any meaningful (business or other) relationship to proceed. In Asian and in the Middle East cultures the people would first feel out if they can trust the other party. Only after a sufficient amount of interaction and only after they feel a high level of inter-personal confidence, only after they feel that the other party is trustable, will they proceed to do the discussions of substance. Such a "feeling out" process may take the form of socializing and it take many hours or even several days. The other party has to earn his trust and, more importantly, keep it after the business deal is made and the agreement's work begins.

Direct human contact and interaction in a face-to-face way would be the more positive approach to generate fuller communication and meaningful exchange of views and ideas. Knowing ahead of time about the other persons would be the result in better and frank communication. For example, President Franklin D. Roosevelt (FDR) overwhelmingly preferred to know his major international players as persons ahead of time before meeting them (e.g. Stalin). He did so by sending his trusted and personal envoys to meet them beforehand. In knowing their personal points and facets, he knew how to communicate and negotiate with them as actual persons, not some officials or functionaries occupying organizational or official positions. FDR truly believed that successful negotiations require a more human-to-human contacts and truly personal interactions.

\section{The Successful Negotiator's Skills}

A successful international executive or negotiator should possess certain skills for him to be successful. He should have fuller and intimate knowledge of the situation and information about the other persons and organizational situation so he can meaningfully discuss with the other parties (Peleckis, 2014; Scullion and Brewster, 2001). His depth of knowledge and insights should be a source of support for him. It would bolster his self-confidence. 
He should be able to feel the mood of the other people so that he may correctly set the proper tone of communication and discussion. He should correctly gauge the relative strengths of the other persons in a detailed way for all activities that would help him in collaborating such that the other party would be genuinely relieved in his weak areas. Although there are many other desirable attributes, a negotiator can only possess some of them to start with, he must widen and increase his repertoire of skills and develop in greater depth the listed attributes. Doing so would improve his experience and he would be able to effective manage many different future negotiation scenarios.

\section{Characteristics of Successful Negotiation}

Negotiation for the successful negotiator means that in international business he straddles over different cultures, and, he in the course of his work will experience different and unfamiliar cultures, communication styles and operational and physical details. He should be able to transcend these challenges, differences and unfamiliarity (Khakhar and Hussain, 2012). The more diverse he travels and picks up insights in international bargaining and the better he knows about people indifferent countries, the better would be his specific range of facts and information about the different peoples. $\mathrm{He}$ also increases his credibility. He will be more smooth and resourceful and competent in effectively coping with even the most complicated or difficult negotiating scenarios. He will learn and remember all the need specific details, from rules and regulations to the personalities of specific influential people.

Common attribute and appeal on some cultural dimensions can positively help the negotiation process as in the case of a common religion among the negotiators. Such is the case of the negotiators having a common religion and the negotiators do follow a particular religion, as in the study by Richardson and Rammal (2018). The study showed how appealing to a common religion (in this case, Islam) led to a more favorable together-ness and good feeling among the people involved. Cultural intelligence and sensitivity are vital in the negotiation process (Vlajcic et al, 2019). The negotiation outcome was better and the players achieved it with greater ease and without much strain or tension.

Both sides ideally should exert to accommodate and help lighten the difficulties and constraints of each other (Chen and Gerhard, 2015). The cooperative and volunteering nature of each party would further the cause of negation objectives. Each party should refrain from unnecessary argumentativeness and also refrain from the raising of thorny and conflicting issues and topics. Each party should accept the other party's position and respect it. His maturity and understanding, acquired through long, meaningful experience, would go a long way to acquiring a masterful restraint from foolhardy missteps or impulsiveness. He will be smoother and successful in negotiation outcomes.

Individual personalities of the international executive or negotiator can have a significant impact on the nature of negotiations. For example, for those whose personality is serious and lacking in the much needed human touch and kindness, they will experience an uphill challenge in achieving amicable results. On the other hand, those who are blessed with happy and cheerful disposition will have a more pleasant and delightful negotiation process. The negotiator's own disposition may be the starting point for his improvement. This is similar to the plight of a salesman whose own personality and disposition would have a significant impact on the selling process and sales outcomes.

\section{The Life of the Successful International Negotiator}

The international negotiator walks the lonely way. He has at hand no friendly headquarters' colleagues and helpful staff and factory managers and engineers and cost accountants within an arm's reach. There is not the supportive superior boss one floor up whom he can personally implore and get much needed price concessions or better terms to clinch the deal. He has to deal with them form distance. He does not have the close help of colleagues to render analyses of a complex situation and help him out of the woods and someone to go through the many details and no family to absorb the shocks of the many pressure weeks overseas. He is a lonely man. He is expected to be self-sufficient, self-reliant, self-contained and full of composure. He is not expected to look for a shoulder to lean on. He is his own resource. He is his own power house of knowledge and data, his own emotional reservoir and his own bottomless well of intuition. He may be paid highly for his job, some may say, but not enough, not really. The rigorous of his being on the move is too much and almost no amount of money can make up for it.

He faces two pressures: (a) One is to be successful in his assignment, which is to accomplish a favorable or optimal deal. That would mean that he should have even greater authority from his headquarters, greater flexibility, presence of mind and powers of persuasion. (b) On the other hand, he is supposed to helpful to the other party. He thus is always at cross roads, always at decision junctures, always at doubt as to which is the better way. His feelings are of did-I-do-the-right-thing, and, what-if-I-had-done-something-else. Over time, he gets used to that, to live with an ambiguity and uncertainty. He gets used to that unsure feeling because there are the goals of negotiations in front of him and, at the same time, he has to make sure that he complies with the constraints placed upon him by the headquarters. These thoughts and feelings go with him wherever he goes. They stay with him in his lonely moments, at the back of his mind when he is with people, when he is being entertained as when he reflects. These thoughts are in the sidelines even when he strives and concentrates to come up with solutions for the other party. He is his own counsel, advisor, partner 
in negotiations, sounding board, confidante, and his own final decision maker.

An example of how much work is involved during the international travel during negotiations involving mega deals, one has only to recall the experience which Mr. Ratan Tata, the remarkable CEO of the Tata group of India, went through when he and his team were reviewing and finalizing the numerous details (some 1,200 pages of legal document) in hotel rooms for purchasing Corus, a British and Dutch steel company (Wa, 2015). He had to repeatedly go through this long document multiple times. This process involved long and many days. He was making the deal to make Corus a part of Tata Steel.

The fear of foreign travels in certain regions may be warranted. For example, the fear of kidnapping, being held hostage, being robbed or cheated are some of the real threats for the negotiator as a person. The international negotiator must be on his best guard and be careful (Schotter and Beamish, 2011). Yet he has to prod in his travel, meet people, negotiate and achieve his goals. He learns to live with this uncertainty and concern for self.

The international executive or negotiator would have to contend with the threats of international terrorism, violence and other personal threats to his personal safety. The personal safety and well-being should be his instinctive concern. He should have a certain level of fear because that would make him cautious. That is desirable. He will be extra careful and observant.

The international negotiator is an international traveler who has to do his work beforehand and in the face of a variety of different situations, problems, conditions of living and work, and challenges. All of these are different from those he would encounter in his own country.

The length of negotiations can be unpredictable, as a seemingly simple negotiation turns into a complex one, an apparent straightforward and logical process turns into a knotty and difficult negotiation problem, and other unpredictable negotiation situations arise. What might have been a few days negotiation may eventually be prolonged into a long, seemingly unending month-long negotiation process, each day of which is arduous and patience-challenging!

An international negotiator may have a series of many negotiations in many different countries; and, if even one deal takes much more time, he could be on the road for two months before he can be expected home. And he is expected to do all this without showing jet lag, travel fatigue, or disorientation, as he tries to adjust from one negotiation situation to the next as he weaves his path through a series of myriad negotiation problems. He must appear fresh, alert, attentive, sensitive, courteous, polite, responsive, and understanding - all these he must show even though his nerves may be raw and he may long to relax in his own home. He must synchronize his pace, approach and content of negotiation to those of his host. He must adapt to suit to the host country's preferred style of negotiation. He cannot show any awkwardness, ineptness, insensitivity, personal discomfort, hostility, inertia, exasperation, boredom, futility, bad taste, or lack of concern as he projects the images of himself, his company, and his home country during these negotiations.

\section{Conclusions and Recommendations for Successful Negotiation Practices}

The negotiation and communication styles and processes are grounded in a particular society's culture and values (Ribbink and Curtis, 2014). Culture provides the basis for human interaction; while communication, through language, is the conduit through which the culture of a society expresses itself, of how to live. Culture provides guidance and construct of how a human will relate to his peoples and environments.

Specific cultural attributes of a particular society, community or country would influence the very fundamentals of human interactions and transactions, including negotiations and bargaining. For example, some countries are rational and rely only on factual data and the product's performance tests and would suspect if the selling party tries to praise its products for a hard sell. Negotiations are strictly business-like and precise. On the other hand, other countries which are more emotional are more relationship oriented and have a long term view of negotiations. They will first decide if they trust the other part y and only then would do business, relying on relationship as the foundation for interactions.

\subsection{Recommendations for the International Negotiator}

While negotiation styles and preferred processes are very much dependent on the individual negotiator, there are some general suggestions. They are aimed at providing broad general guidelines and an individual negotiator may want to adapt so that it would fit his unique personality. Growth in one's negotiation personality style would most likely show maturity for a busy international negotiator. Hi knowledge of specific cultural nuances and differences would expand in time. This would broaden his cultural acumen.

\subsection{Fully Prepare Before Departure and Keep Updating on the Trip}

A successful negotiator will thoroughly prepare before leaving for his negotiation trip. Rule of thumb, it is often said, is for every hour of negotiation, the negotiator would need one day of pre-departure preparation. He would think up of 
many scenarios and questions that could come up during the negotiations. He studies the other party, his personality, his organizational culture, so that he communicates effectively.

\subsection{Develop Long Term View Good Relationship}

Beyond the concern for immediacy and making this a one shot deal, the negotiator focus his building a nurturing a strong bond of stable, genuine relationship and views it to a long term relationship. He would proceed with great respect and consideration for the other persons. Such a steady and sincere approach would win him to the other party. Building organizational relationship would yield long term fruitful results for both parties. Part of this process is the socializing and diner parties and sight-seeing and meeting with more organizational people and their families too.

\subsection{Focus on Common Ground that Could Bind the Two Parties Together}

The successful negotiator will find the common interest and will emphasize them. He will understand the other part's specific needs and incorporate them in his grand plan as a solution. He would incorporate his organization's capability to serve them, and, in doing so, he will emphasize the. This is his skill of successful negotiation. He stresses and works on the issues that bind the two parties together rather than those that tear them apart. The focus is on mutual benefits rather than a one-sided approach.

\subsection{Openness to Other Cultures}

The successful negotiator is very open to other cultures without prejudice or stereotyping. He embraces them with full zeal and show happiness in dealing with the people (Fang, Schaumburg and Fjellström, 2017). He is balanced and he is generous as if he were dealing with people of his own kind. He is keen and interested in learning about other cultures and wants to enjoy their unique characteristics. He respects every aspect of the culture.

\subsection{Be an Active Listener}

The successful negotiator focuses on what the other party is communicating and he tries to put himself in their shoes. He understands them in their situation and context. He picks up cues and diagnoses the other party's problems and he addresses them as well as he can.

\subsection{Judges the Correct Pace and Approach}

$\mathrm{He}$ is astute in judging the proper pace needed in the given situation, and, he responds with issues as proper timing and pace of the process. Such efforts will put the other party at ease. Because they are comfortable in dealing with him, the negotiations will be more fruitful.

\subsection{Correctly Judge the Negotiation Situation}

He is focused on sizing up the negotiation situation and adapts his strategies accordingly. His effectiveness lies in his tailoring himself to the needs of the negotiation situation at the various stages of the negotiation process.

\subsection{Conclusion}

The successful negotiator shows maturity and wisdom and, to an extent, generosity in his dealings with the other party. His wealth of experience in negotiating with different peoples and cultures make him versatile and resourceful. His unique blend of insights of different peoples of different industries, technologies, businesses, in addition to peoples of different cultures, provide him with invaluable depth and breadth that make him successful. His success as an international executive and negotiator make him more valuable to his own organization, in addition to the other international organizations viewing him as a preferred partner in their dealings. His stature and reputation will flourish within his own organization; his effectiveness in negotiation with other organizations will also flourish. As a successful negotiator he seeks long term mutual, equitable solutions which benefit both parties.

\section{References}

Chen, S., \& Gerhard, W. (2015). An approach to complex agent-based negotiations via effectively modelling unknown opponents. Expert Systems With Applications, 42(5), 2287-2304. https://doi.org/10.1016/j.eswa.2014.10.048

Collins English Dictionary, Complete and Unabridged. On-line Edition. 2012. HarperCollins Publishers.

Fang, T., Schaumburg, J., \& Fjellström, D. (2017). International Business Negotiations in Brazil. Journal of Business \& Industrial Marketing, 32(4), 591-605. https://doi.org/10.1108/JBIM-11-2016-0257

Fells, R., Helen, R., Peter, P., \& Ursula, F. (2015). Unraveling Business Negotiations Using Practitioner Data. Negotiation and Conflict Management Research, 8(2), 119-136. https://doi.org/10.1111/ncmr.12050

Khakhar, P., \& Hussain, G. R. (2012). Culture and business networks: International business negotiations with Arab managers. International Business Review, 12, 23-55. 
Merriam-Webster's Dictionary of Synonyms: A Dictionary of Discriminated Synonyms with Antonyms and Analogous and Contrasted Words. 1984. Springfield, MA.

Moran, R. T., \& William, G. S. (1991). Dynamics of successful international business negotiations. Houston: Gulf Publishing.

Peleckis, K. (2014). International business negotiations: Innovation, negotiation team preparation. Procedia-Socialand Behavioral Sciences, 110, 64-73. https://doi.org/10.1016/j.sbspro.2013.12.848

Ribbink, D., \& Curtis, M. G. (2014). The impact of cultural differences on buyer-supplier negotiations: An empirical study. Journal of Operations Management, 32(3), 114-126. https://doi.org/10.1016/j.jom.2014.01.004

Richardson, C., \& Rammal, H. G. (2018). Religious belief and international business negotiations: Does faith influence negotiator behaviour? International. Business Review, 27(2), 401-409. https://doi.org/10.1016/j.ibusrev.2017.09.007

Schotter, A., \& Beamish, P. W. (2011). Performance effects of MNC headquarters-subsidiary conflict and the role of boundary spanners: The case of headquarter initiative rejection. Journal of International Management, 17(3), 243-259. https://doi.org/10.1016/j.intman.2011.05.006

Scullion, H., \& Brewster, C. (2001). The management of expatriates: Messages from Europe. Journal of World Business, 36(4), 346-365. https://doi.org/10.1016/S1090-9516(01)00060-8

Situmorang, R., \& Japutra, A. (2019). Foreign versus local managers: Finding the perfect leaders for multinational hotel $\begin{array}{llll}\text { subsidiaries. International Journal of Hospitality } & \text { Management, 78, }\end{array}$ https://doi.org/10.1016/j.ijhm.2018.11.015

Vlajcic, D., Caputo, A., Marzi, G., \& Dabie. (2019). Expatriates managers' cultural intelligence as promoter of knowledge transfer in multinational companies. Journal of Business Research, 94, 367-377. https://doi.org/10.1016/j.jbusres.2018.01.033

Wa, Y. (2015). Understanding "the elephants in the room": The roadmap to prepare for business negotiations in India and China. Journal of International Business and Law, 67, 23-35.

\section{Copyrights}

Copyright for this article is retained by the author(s), with first publication rights granted to the journal.

This is an open-access article distributed under the terms and conditions of the Creative Commons Attribution license which permits unrestricted use, distribution, and reproduction in any medium, provided the original work is properly cited. 